Maria M. Zestos MD, Alison S. Carr MB BS, Georgina McAuliffe MB BS, Helen S. Smith MB BS, Nancy Sikich RN, Jerrold Lerman MD FRCP

\title{
Subhypnotic propofol does not treat postopera- tive vomiting in children
after adenotonsillectomy tive vomiting in children
after adenotonsillectomy
}

Purpose: To investigate the efficacy of a subhypnotic dose of propofol to treat vomiting in children after adenotonsillectomy.

Methods: Two hundred and fifty-two children, aged 2-12 yr, underwent a standardized anaesthetic opioid administration, and postoperative care after adenotonsillectomy, adenoidectomy or tonsillectomy. A prospective, double-blindad, placebo-controlled study was performed in 70 of the patients who retched or vomited after surgery and who had intravenous access. Patients were assigned randomly to receive either $0.2 \mathrm{mg} \cdot \mathrm{kg}^{-1}$ propofol $(n=35)$, or placebo (intralipid 10\%, $n=35$ ).

Results: The overall incidence of vomiting during the first 18-24 hr was 50\%. Of those who had received propofol after the first episode of vomiting, $63 \%$ relapsed requiring a rescue antiemetic compared with $57 \%$ of those who had received intralipid $(P=N S)$. Of the children who received propofol, $54 \%$ experienced pain on injection and $46 \%$ were mildly sedated compared with $3 \%$ and $11 \%$, respectively, in the placebo group $(P<0.003)$.

Conclusion: We conclude that an intravenous bolus of $0.2 \mathrm{mg} \cdot \mathrm{kg}^{\prime}$ propofol is not effective in the treatment of postoperative vomitng in children after adenotonsillectomy when a standardized anaesthetic with thiopentone, halothane, nitrous oxide, and $1.5 \mathrm{mg} \cdot \mathrm{kg}{ }^{\prime}$ codeine phosphate is used, but it does cause sedation and pain on injection.

Objectif : Vérifier l'efficacité d'une dose subhypnotique de propofol administrée après une adéno- amygdalectomie pour le traitement des vomissements chez des enfants.

Méthodes : [jeux cent cinquante-deux enfants, âgés de 2 à 12 ans, programmés pour adéno-amygdalectomie ou amygdalectomie ont été opérés sous anesthésie générale suivie d'une analgésie aux morphiniques et de soins postopératoires standardisés. Soixante-dix patients qui faisaient des efforts pour vomir ou vomissaient ont été choisis pour cette étude prospective, en double aveugle et contrôlée avec placebo. Les patients étaient désignés aléatoirement pour recevoir soit $0,2 \mathrm{mg} \mathrm{kg}^{-1}$ de propofol $(n=35)$ soit le placebo (intralipid $10 \%, n=35$ )

Résultats : Pendant les 18 à $36 \mathrm{~h}$ initiales, l'incidence totale des vomissements était de $50 \%$. Parmi ceux qui avaient reçu du propofol après un premier épisode de vomissements, $63 \%$ ont récidivé et ont eu besoin de l'antiémétique de sauvetage comparativement aux $57 \%$ qui avaient reçu de l'intralipid $(P=N S)$. Parmi les enfants qui recevaient du propofol. $54 \%$ se sont plaints de douleur au moment de l'injection et $46 \%$ étaient sous sédation légère compa ativement à $3 \%$ et $11 \%$ dans le groupe placebo $(P<0,003)$.

Conclusion : Du propofol $0.2 \mathrm{mg} \cdot \mathrm{kg}^{-1}$ en bolus iv ne constitue pas un traitement efficace des vomissements postopératoires après une adéno-amygdalectomie chez des enfants anesthésiés au thiopentone, halothane, protoxyde d'azote: suivie d'une analgésie produite par $1.15 \mathrm{mg} \cdot \mathrm{kg}^{\prime}$ de phosphate de codéine. De plus, ce traitement est sédatif et frovoque de la douleur au moment de l'injection.

From the Department of Anaesthesia and The Research Institute, The Hospital for Sick Children, University of Toronto, Toronto, Ontario, Canada M5G IX8.

Address correspondence to: Dr. J. Lerman, The Hospital for Sick Children, Dept. of Anacsthesia, Room 2212, 555 University Avenure,

Toronto, Ontario M5G 1X8. Phone: (416) 813-7445; Fax: (416) 813-7543; E-mail: lerman@anaes.sickkids.on.ca

Accepted for publication December $6,1996$. 
$\mathrm{P}$ OSTOPERATIVE vomiting (POV) causes considerable discomfort to children as well as delayed discharge and unexpected admission to hospital. ${ }^{1}$ Many factors affect the incidence of postoperative nausea and vomiting including the type of surgery, the anaesthetic agents used, opioid administration, ambulation and postoperative fluid intake. Propofol has been shown to decrease the incidence of postoperative nausea and vomiting when used for induction and maintenance of anaesthesia ${ }^{2}$ and has been used successfully in oncology patients as a lowdose continuous infusion to treat nausea and vomiting. ${ }^{3}$ However, its effectiveness as a bolus therapeutic intervention for POV is controversial. ${ }^{4,5}$ The inability to demonstrate the effectiveness of a bolus of propofol to treat POV in these studies may be due to confounding variables resulting from different anaesthetic techniques and perioperative management. Accordingly, we evaluated the antiemetic effect of a subhypnotic propofol bolus in the treatment of POV after adenoidectomy or tonsillectomy in children who had received a standardized anesthetic technique and postoperative care.

\section{Methods}

With IRB approval and written informed consent, children scheduled for adenotonsillectomy (including tonsillectomy or adenoidectomy) were enrolled in this prospective double-blinded randomized study until 70 children had been treated for vomiting. All children received a standardized anaesthetic technique and postoperative pain management. Anaesthesia was induced with $5 \mathrm{mg} \cdot \mathrm{kg}^{-1}$ thiopentone, $0.0 \mathrm{lmg} \cdot \mathrm{kg}^{-1}$ atropine, followed by $2 \mathrm{mg} \cdot \mathrm{kg}^{-1}$ succinylcholine to facilitate tracheal intubation. Anaesthesia was maintained with oxygen, nitrous oxide, and halothane $1-2 \%$. Children received $1.5 \mathrm{mg} \cdot \mathrm{kg}^{-1}$ codeine im intraoperatively and $15 \mathrm{mg} \cdot \mathrm{kg}^{-1}$ acetaminophen $p r$ in the recovery room. The trachea was extubated with the patient either awake or asleep according to the anaesthetist's preference. After discharge from the recovery room, all children were observed in a short stay unit for four to six hours. Postoperative pain was treated with liquid (10-15 $\mathrm{mg} \cdot \mathrm{kg}^{-1}$ acetaminophen and/or codeine (1-2 mg. $\left.\mathrm{kg}^{-1}\right)$ acetaminophen every four hours as needed. Criteria for discharge from hospital included the ability to tolerate oral fluid intake $\left(15 \mathrm{ml} \cdot \mathrm{kg}^{-1}\right)$.

Children who retched or vomited postoperatively were randomly assigned to receive either $0.2 \mathrm{mg} \cdot \mathrm{kg}^{-1}$ propofol or an equivalent volume of placebo (intralipid $10 \%) i v$ provided intravenous access was available and there was no history of sleep apnea. Treatment assignment was determined using random number tables to assign 35 patients to each of the two groups. The anaes- thetist who administered the antiemetic treatment was unaware of the treatment assignment. Pain at the time of injection of the treatment and the maximum sedation within five minutes of the treatment were recorded. If the child vomited a second time, $1 \mathrm{mg} \cdot \mathrm{kg}^{-1}$ dimenhydrinate was given. The number of episodes of POV, time to the next episode, oral fluid intake, administration of pain medication and the use of rescue antiemetic (dimenhydrinate) medication were recorded. The parents of all children were telephoned 18-24 $\mathrm{hr}$ after surgery and all episodes of vomiting after discharge from the hospital were reported.

The sample size was calculated using an $\alpha_{2}=0.05$, $\beta=0.2$, a $70 \%$ incidence of relapse of vomiting after placebo (intralipid) and a 35\% incidence of relapse after propofol. ${ }^{4}$ This yielded a sample size of 31 patients per group. ${ }^{6}$ To take into account the possibility that the incidence of vomiting between the treatments might be smaller than expected, 35 children were enrolled in each group.

Data were analyzed using the Student's t-test, Chisquare analysis and Fisher's exact test. A $P$ value $<0.05$ was considered statistically significant.

\section{Results}

Of the 252 children who were enrolled, 70 completed the study. An additional 44 children vomited postoperatively but did not have ip access at the time of the vomiting episode. Accordingly, they remained part of the overall incidence of POV but were considered ineligible for randomization and participation in the study. We were not notified about three more children who vomited postoperatively and, thus, they were not treated. One child vomited a copious amount of fresh blood, had her nose packed and throat cauterized on the ward by the otolaryngologist and was excluded from the randomization. The overall incidence of POV before treatment was $50 \%$ with $94 \%$ of the episodes occurring before discharge from hospital and $6 \%$ occurring only after discharge.

Of the 70 children who completed the study, demographic data did not differ between the two groups (Table I). None of the children who received propofol lost consciousness or developed respiratory distress. Children who received propofol were more likely to be sedated $(46 \%$ vs $11 \%, P<0.003)$ and to complain of pain at the time of injection of propofol $(54 \%$ vs $3 \%, P<0.0001)$ than were those who received placebo (Table II). Few children vomited within either $30 \mathrm{~min}$ or one hour after either treatment (Table II). The total number of episodes of vomiting was similar in the two groups (Figure 1). There was no difference in the time to relapse of vomiting after 
TABLE I Demographic data

\begin{tabular}{lcclllll}
\hline & No. & Age & Wt. & Anaesthetic & \multicolumn{2}{l}{ Surgical Procedure } \\
& & $(\mathrm{yr})$ & $(\mathrm{kg})$ & Time $(\mathrm{br})$ & TerA & A only & Tonly \\
\hline Propofol & 35 & 6.5 & 26.6 & 0.6 & 30 & 4 & 1 \\
Placebo & 35 & 5.7 & 23 & 0.58 & 26 & 7 & 2 \\
P value & & NS & NS & NS & & & \\
\hline
\end{tabular}

intervention (Figure 2). Oral opioid requirement ( $14 \%$ vs 20\%), the incidence of admission for POV $(37 \%$ vs $29 \%)$ and the incidence of vomiting relapse (62\% vs 57\%) were similar in the propofol and the placebo groups, respectively.

\section{Discussion}

Adenotonsillectorny is a reasonable surgical paradigm for a study of PCIV since it is associated with a high incidence of postoperative vomiting; in this study $50 \%$. Many factors affect the incidence of postoperative vomiting including: the type of surgery and anaesthetic technique, the administration of opioids and antiemetics, oral fluid intake and ambulation. Although we controlled for most of these factors in this study, $0.2 \mathrm{mg} \cdot \mathrm{kg}^{-1}$ propofol, a subhypnotic dose, did not prevent relapse. This may be explained, in part, by the observation that children vomit only once (Figure 1) or vomit several hours apart (Figure 2) after adenotonsillectomy. Indeed, only one of the 70 children vomited within $30 \mathrm{~min}$ after his/her treatment, the time interval Borgeat reported a subhypnotic dose of propofol to be effective. This interval almost certainly exceeds the half-life of a single dose of iv propofol. Thus, even if propofol were effective for treating vomiting after adenotonsillectomy, its antiemetic effect may have dissipated before subsequent episodes of POV had occurred.

A second possible explanation for our inability to detect an antiemeric effect by propofol relates to the mechanism of vomiting after adenotonsillectomy. Postoperative vomiting after adenotonsillectomy has been attributed to the presence of swallowed blood in the stomach, intraoperative distraction of the jaw and stretching of the mucosa of the oropharynx, or inges-

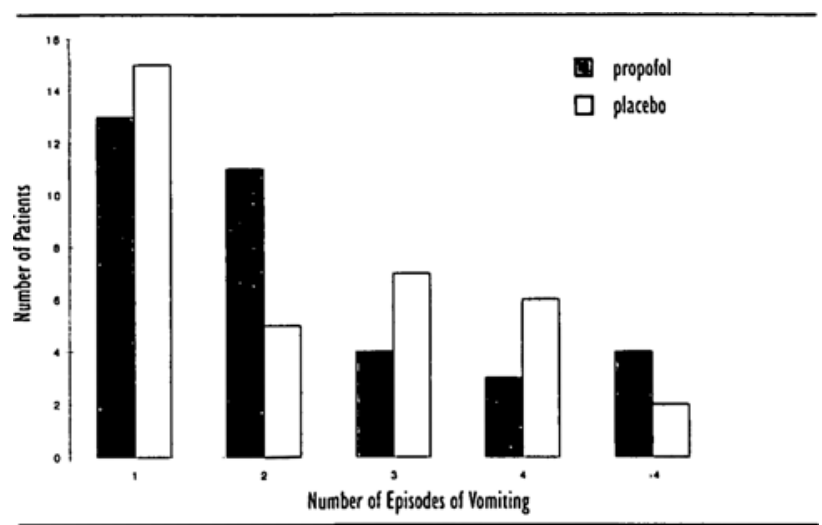

FIGURE 1 The total number of vomiting episodes were similar in both the propofol and placebo groups.

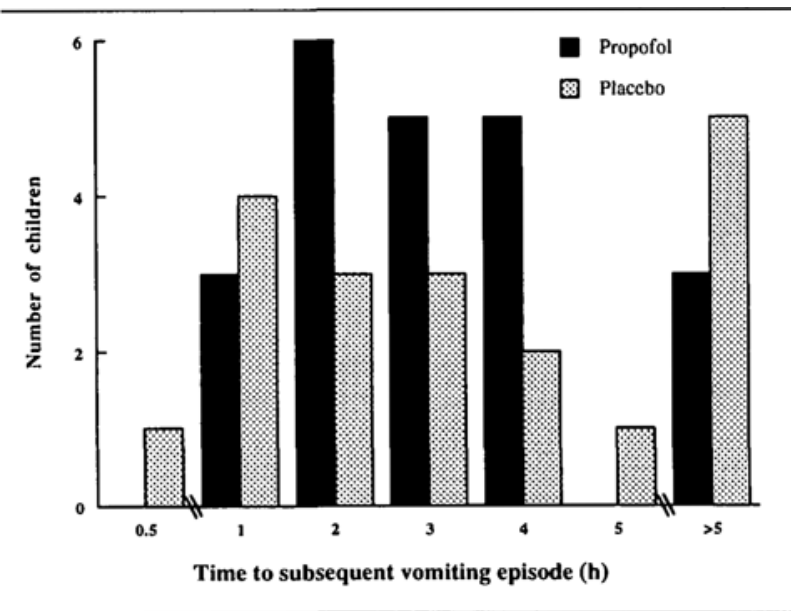

FIGURE 2 There was no difference in the time to relapse of vomiting after intervention. Most children who vomit again vomit several hours later.

tion of oral fluids postoperatively. Blood may stimulate POV by activating $5-\mathrm{HT}_{3}$ in the stomach and upper gastrointestinal tract. This may explain the effectiveness of $5-\mathrm{HT}_{3}$ receptor antagonists in preventing vomiting after adenotonsillectomy. Centrallymediated POV via the chemoreceptor trigger zone may also occur and it is possible pharmacologically that propofol acts via dopamine-2 receptor antagonism in this area of the brain. ${ }^{7}$ Thus, the lack of effi-

TABLE II The effect of treatment

\begin{tabular}{|c|c|c|c|c|c|c|c|c|c|c|}
\hline \multirow[b]{2}{*}{ Treatment } & \multirow[b]{2}{*}{ No. } & \multicolumn{3}{|c|}{$\begin{array}{l}\text { Relapse of Vomiting } \\
\text { after Intervention }\end{array}$} & \multirow{2}{*}{$\begin{array}{l}\text { No. of } \\
\text { Relapse }\end{array}$} & \multicolumn{2}{|c|}{$\begin{array}{l}\text { Episodes of } \\
\text { Vomiting * }\end{array}$} & \multirow{2}{*}{$\begin{array}{l}\text { Time to } \\
\text { Vomiting }\end{array}$} & \multicolumn{2}{|l|}{$\begin{array}{l}\text { Pain } \\
\text { on }\end{array}$} \\
\hline & & $0.5 \mathrm{hr}$ & $1 \mathrm{hr}$ & Total & & med & n (range) & & Injection & Sedation \\
\hline Propofol & 35 & $10 \%$ & $3 \%$ & $62 \%$ & 22 & l & $(0-6)$ & $3.4 \mathrm{hr}$ & $54 \%$ & $46 \%$ \\
\hline Placebo & 35 & $3 \%$ & $14 \%$ & $\mathbf{5 7 \%}$ & 19 & 1 & $(0-6)$ & $3.6 \mathrm{hr}$ & $3 \%$ & $11 \%$ \\
\hline$P$ value & & NS & NS & NS & NS & NS & NS & NS & $<0.0001$ & $<0.003$ \\
\hline
\end{tabular}

* vomited after initial episode of vomiting and treatment 
cacy of propofol may also be attributed to a failure to block the receptor responsible for POV after this type of surgery.

A third possible explanation for the failure of propofol to prevent a relapse of POV is a type II error due to a low power of this study. Although a much larger sample size may have yielded a statistically significant difference in the treatment of POV, it is unlikely to have resulted in a clinically significant difference. Our incidence of POV relapse in the placebo group (57\%) was less than expected (70\%), however, the incidence of repeat POV was virtually unchanged with the use of propofol (62\%). On the basis of these values, there is no clinical difference in the incidence of relapsed POV between the two groups. Moreover, the number of patients required to detect a statistically significant difference in the incidence of POV between the groups would be too large to justify such a clinical study.

This study demonstrated that $0.2 \mathrm{mg} \cdot \mathrm{kg}^{-1}$ propofol $i v$ is not effective in the treatment of POV after adenotonsillectomy in children. Two other studies also evaluated a subhypnotic dose of propofol to treat POV but under conditions that differed from the present study. Borgeat $e t$ al. studied adults undergoing minor gynaecological, orthopaedic or digestive tract surgery and used both nausea and vomiting as endpoints. ${ }^{4}$ They found that iv propofol decreased the incidence of repeat vomiting within $30 \mathrm{~min}$ of the initial episode from $73 \%$ in the placebo group to $42 \%$ in the propofol group. Litman studied the incidence of POV in children but failed to control many of the variables that are known to affect vomiting including anaesthetic technique, type of surgery, and postoperative pain control. ${ }^{5}$ These differences prevent a direct comparison of those studies to the present study.

Propofol has been shown to prevent and treat POV in several studies. When used for induction and maintenance of anaesthesia in children undergoing otolaryngological surgery, propofol decreases the incidence of POV. ${ }^{8}$ Although expensive, this is a viable alternative and may indeed prove to be cost-effective if the rate of adnission to hospital for vomiting is decreased. When given as a continuous infusion, ${ }^{9}$ propofol is also a viable option in adults who are inpatients and who experience refractory nausea and vomiting. This latter technique, however, is impractical and costly in children since the anaesthetic times are brief and the time to discharge from hospital should also be brief. We therefore evaluated bolus intravenous therapy to treat vomiting as a practical and less costly technique.
At the time of this study, we required that all children tolerated $15 \mathrm{ml} \cdot \mathrm{kg}^{-1}$ of oral clear fluids after surgery in order to be discharged from hospital. Many institutions, including our own no longer insist that children tolerate oral fluids postoperatively as a requirement for discharge based on evidence that oral fluids trigger POV. ${ }^{1}$ To minimize the risk of dehydration if oral fluids are not ingested postoperatively for an extended period, we infuse $10-15 \mathrm{mg} \cdot \mathrm{kg}^{-1}$ of a balanced salt solution iv during surgery. In the absence of postoperative oral fluid intake, the incidence of postadenotonsillectomy vomiting at our institution has greatly diminished.

We conclude that at a subhypnotic dose $(0.2$ $\mathrm{mg} \cdot \mathrm{kg}^{-1}$ ), propofol does not prevent POV in children after adenotonsillectomy, but does cause mild sedation and is often painful on injection. A subhypnotic dose of propofol does not offer any benefit when the frequency of repeat POV is small and the time between episodes is prolonged.

\section{References}

I Scbreiner MS, Nicolson SC, Martin T, Whitney L. Should children drink before discharge from day surgery? Anesthesiology 1992; 76: 528-33.

2 Weir PM, Munro HM, Reynolds PI, Lewis IH, Wilton NCT. Propofol infusion and the incidence of emesis in pediatric outpatient strabismus surgery. Anesth Analg 1993; 76: 760-4.

3 Scher CS, Amar D, McDowall RH, Barst SM. Use of propofol for the prevention of chemotherapy-induced nalisea and emesis in oncology patients. Can J Anaesth 1992; 39: 170-2.

4 Borgeat $A$, Wilder-Smith $O H G$, Saiah M, Rifat K. Subhypnotic doses of propofol possess direct antiemetic properties. Anesth Analg 1992; 74: 539-41.

5 Litman RS, Berger AA, Chbibber $A$. Efficacy and safety of propofol when used to treat postoperative emesis in children. Anesthesiology 1994; 81: A18.

6 Cohen J. Statistical Power Analysis for the Behavioral Sciences, 2nd ed. Hillsdale, NJ: Lawrence Erlbaum Associates, 1988: 179-206.

7 Diflorio $T$. Is propofol a dopamine antagonist? (Letter) Anesth Analg 1993; 77: 200.

8 Borgeat A, Popovic V, Meier D, Schwander D. Comparison of propofol and thiopental/halothane for short-duration ENT surgical procedures in children. Anesth Analg 1990; 71: 511-5.

9 Schulman SR, Rockett CB, Canada AT, Glass PSA. Long-term propofol infusion for refractory postoperative nausea: a case report with quantitative propofol analysis. Anesth Analg 1995; 80: 636-7. 